\title{
Deep Brain Stimulation Target Selection for Parkinson's Disease
}

\author{
Christopher R. Honey, Clement Hamani, Suneil K. Kalia, Tejas Sankar, Marina \\ Picillo, Renato P. Munhoz, Alfonso Fasano, Michel Panisset
}

\begin{abstract}
During the "DBS Canada Day" symposium held in Toronto July 4-5, 2014, the scientific committee invited experts to discuss three main questions on target selection for deep brain stimulation (DBS) of patients with Parkinson's disease (PD). First, is the subthalamic nucleus (STN) or the globus pallidus internus (GPi) the ideal target? In summary, both targets are equally effective in improving the motor symptoms of PD. STN allows a greater medications reduction, while GPi exerts a direct antidyskinetic effect. Second, are there further potential targets? Ventral intermediate nucleus DBS has significant long-term benefit for tremor control but insufficiently addresses other motor features of PD. DBS in the posterior subthalamic area also reduces tremor. The pedunculopontine nucleus remains an investigational target. Third, should DBS for PD be performed unilaterally, bilaterally or staged? Unilateral STN DBS can be proposed to asymmetric patients. There is no evidence that a staged bilateral approach reduces the incidence of DBS-related adverse events.
\end{abstract}

RÉSUMÉ: Choix de cible en matière de stimulation cérébrale profonde dans le cas de la maladie de Parkinson. C'est durant le symposium «Stimulation cérébrale profonde (SCP)-Fête du Canada » tenu à Toronto les 4 et 5 juillet 2014 qu'un comité scientifique a invité des experts à aborder trois questions fondamentales en ce qui regarde le choix de cible en matière de SCP dans le cas de patients atteints de la maladie de Parkinson (MP). Premièrement, il leur a été demandé si le noyau sous-thalamique (NST) ou le globus pallidus interne (GPi) constituaient une cible idéale. En résumé, il a été établi que ces deux cibles s'équivalent quant à la capacité d'atténuer les symptômes moteurs de la MP. À ce sujet, si le NST permet une réduction plus importante de la consommation de médicaments, le GPi, lui, exerce un effet anti-dyskinétique direct. Deuxièmement, on a demandé aux experts dans quelle mesure il pouvait y avoir d'autres cibles potentielles. Ainsi, bien que la SCP du noyau ventral intermédiaire procure un avantage important à long terme, elle demeure une avenue insuffisante en ce qui a trait aux autres aspects moteurs de la MP. Soulignons que la SCP de la région sous-thalamique postérieure contribue aussi à réduire les tremblements. Quant au noyau pédonculopontin, il demeure une piste de recherche à explorer. Enfin, est-ce que la SCP devrait être effectuée de façon unilatérale, bilatérale ou être échelonnée en ce qui a trait à des cas de MP ? La SCP unilatérale du NST peut être proposée à des patients dont la symptomatologie est asymétrique. De plus, aucune preuve ne permet de conclure qu'une stimulation bilatérale échelonnée entraîne une réduction de la fréquence des manifestations indésirables liées à la SCP.

Keywords: deep brain stimulation, globus pallidus internus, movement disorder, movement disorder surgery, Parkinson's disease, subthalamic nucleus, surgical target, ventral intermediate nucleus

doi:10.1017/cjn.2016.22

Can J Neurol Sci. 2017; 44: 3-8

During the "DBS Canada Day" symposium held in Toronto July 4-5, 2014, the scientific committee invited experts to share their knowledge of target selection for deep brain stimulation (DBS) of patients with Parkinson's disease (PD). Experts were provided with selected topics for which they were asked to summarize the current literature and highlight what was known and what was still controversial within the field. The topics were divided into three questions. First, is the subthalamic nucleus (STN) or the globus pallidus internus (GPi) the ideal target for DBS in PD? Second, are there other potential targets for DBS in PD? Third, should DBS for PD be performed unilaterally, bilaterally or staged?

These are the questions facing functional neurosurgeons in Canada on a daily basis. This paper attempts to distill the current literature in this area into a succinct summary of what is known, what is often done, and what needs to be studied. This summary will be of interest for both surgeons new to the field and for non-surgeons who may wonder what controversies are facing their surgical colleagues. Our surgical colleagues may find this a timely reference, highlighting what needs to be explored in our

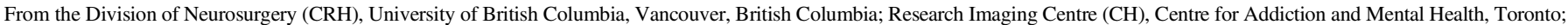

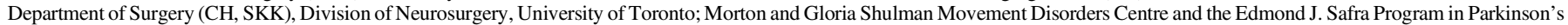

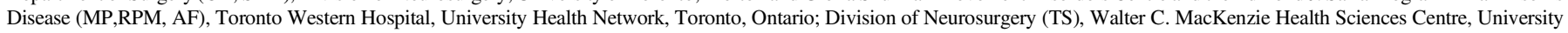

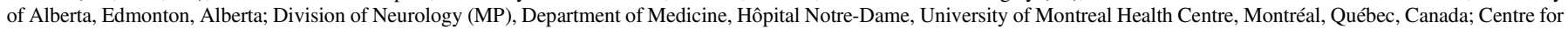
Neurodegenerative Diseases (CEMAND) (MP), Neuroscience Section, Department of Medicine and Surgery, University of Salerno, Salerno, Italy.

Received August 25, 2015. Final Revisions Submitted January 20, 2016.

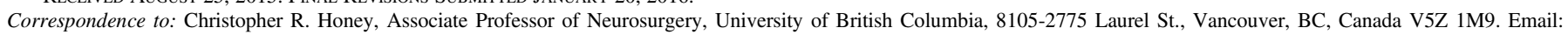
chris.honey@telus.net 
field and how tenuous the bases for some of our current practices are.

The original symposium was sponsored by Medtronic (conflict of interest detailed below). The final report has no industry specific recommendations and was carefully screened to avoid any potential bias.

\section{IS THE STN OR THE GPI THE IDEAL TARGET FOR DBS IN Parkinson's Disease?}

The ideal DBS target for the treatment of PD remains controversial. High frequency stimulation in either the STN or GPi has been shown to improve the motor symptoms of the disease. ${ }^{1}$ A comparison of the benefits of stimulating STN versus GPi has been carried out in different studies. ${ }^{2-11}$ Initial randomized ${ }^{2,5}$ and non-randomized trials (e.g. conducted by the DBS study group) ${ }^{3}$ comparing these targets showed no major differences in efficacy. These same results have been largely replicated in follow-up studies published by the DBS study group at three to six years after surgery, ${ }^{6,10}$ but not in some open label reports. ${ }^{4}$ To help address controversial aspects of target selection, randomized controlled trials with blinded scoring have been designed. ${ }^{9,11}$ In particular, the Veterans-Affairs study included 299 PD patents randomized to receive DBS in either target. ${ }^{9}$ No significant differences in efficacy were found between patients receiving GPi or STN DBS. ${ }^{9}$ The primary outcome was the change in motor function, as blindly assessed on the Unified Parkinson's Disease Rating Scale, part III (UPDRS-III), while patients were receiving stimulation but not receiving antiparkinsonian medication. Secondary outcomes included self-reported function, quality of life, neurocognitive function, and adverse events. In summary, most evidence published to date has shown that DBS in either the STN or GPi is equally effective in improving the motor symptoms of Parkinson's disease.

One of the major drivers for recent trials of GPi DBS was the recognition of psychiatric complications after STN stimulation (e.g. depression, hypomania, and suicide, among others). ${ }^{12-16}$ As in most studies on efficacy, those with a blinded design showed no statistically significant differences in the rate of psychiatric complications between targets, ${ }^{18,9}$ though there did appear to be trend toward a somewhat higher incidence with STN DBS. To date, the only consensus in the field is that STN DBS increases the postoperative risk of verbal fluency deficits. ${ }^{12,14,16}$ These verbal deficits are typically detected by neuropsychologists using a battery of tests including the Controlled Oral Word Association Test (COWAT) but, in our experience, are rarely a concern for the patient or their family.

As clinical trials have suggested that both targets are effective in treating the motor symptoms of PD, one may ask whether there are any selected symptoms that may favor the use of one target over the other. Subthalamic DBS allows a meaningful reduction in dopaminergic medication in the post-operative phase, which typically cannot be achieved with GPi stimulation. Consequently, when one of the goals of the surgery is to reduce medication intake (e.g., to improve dopamine dysregulation syndrome or hyperdopaminergic symptoms such as hallucinations and hypomania), the STN may be a better target. When a direct antidyskinetic effect is desired, the GPi may be a better option in patients who do not need medication reduction. ${ }^{17}$ In patients with cognitive and psychiatric symptoms, some centers may favour the GPi over the STN. ${ }^{18}$

\section{Are There Other Potential Targets for DBS IN Parkinson's Disease?}

The ventral intermediate nucleus (Vim) of the thalamus has always been a surgical target for patients with PD and continues to be an option for tremor-dominant patients. More recently, some centres have presented data suggesting that the posterior subthalamic area (PSA) and pedunculopontine nucleus (PPN) may address certain symptoms of PD that are refractory to DBS in the more common areas. Each of these three targets is discussed below.

\section{Ventral intermediate nucleus (Vim) of thalamus}

Deep brain stimulation targeting the Vim was introduced as one of the original targets for tremor in PD. ${ }^{19-21}$ Since the early nineties, Vim has been the target of choice for the surgical treatment of medically refractory essential tremor by DBS. ${ }^{22-26}$ Compared with other contemporary DBS targets (ie. STN or GPi) the Vim cannot currently be visualized on pre-op magnetic resonance imaging (MRI) for target planning. As such, many centres employ targeting paradigms based on a variety of indirect approaches combined with microelectrode recordings, intra-operative macrostimulation and intra-operative clinical assessments. By this combined multimodal approach the DBS lead can be positioned within the Vim maximizing the potential for therapeutic benefit and minimizing thresholds for off-target side effects. The current evidence for Vim DBS in PD has been recently reviewed. ${ }^{27-30}$ Long-term Vim DBS has a significant benefit for tremor control but insufficiently addresses other key motor features of PD. While contralateral tremor benefits greater than $80 \%$ can be sustained over five years in well selected patients, $23,24,29,31-33$ in general there is no improvement in UPDRS III scores, rigidity, akinesia or postural instability. ${ }^{31,23,24,29}$ In those patients who lose anti-tremor benefit with time it is not clear if this is due to adaptation, progression of PD or a combination of both.

Ventral intermediate nucleus DBS may currently be considered in patients with tremor-dominant PD with an associated slow disease progression. If the patient's other symptoms of PD are a significant source of disability at the time of surgery, the multidisciplinary surgical team should consider STN or GPi DBS upfront. Consideration can be made of a second target in a delayed fashion (i.e. STN or GPi DBS after initial Vim DBS or vice versa), as the symptoms progress. If optimal tremor control is not achieved and/or sustained in those patients with STN or GPi DBS upfront, subsequent contralateral Vim DBS is an option.

\section{Posterior subthalamic area (PSA)}

The PSA has a variable definition, which may include the zona incerta $(\mathrm{Zi})$, prelemniscal radiations (Raprl) and/or the area just lateral to the rostral-most portion of the red nucleus. ${ }^{34}$ To date there is no consensus on specific target planning for the PSA; rather, an indirect approach is used to target the general area posterior to the STN and lateral to the red nucleus. Recently the use of PSA DBS has been reviewed by Blomstedt and colleagues $^{34}$ and reports in the literature demonstrate a consistent tremor reduction in PD as well as essential tremor and tremor related to multiple sclerosis. A subset of small, retrospective, non-randomized studies suggest that PSA may provide better tremor control compared to Vim and STN DBS. ${ }^{34-37}$ One group 
has retrospectively shown that PD patients had more improvement in UPDRS III motor scores with stimulation in the PSA region compared to an earlier cohort receiving stimulation within the STN nucleus. ${ }^{36}$

At this time no firm recommendations for PSA DBS can be made. It may be considered for tremor-dominant PD as discussed above for Vim DBS with the possible advantage of also improving other symptoms of PD. Electrode placement may be planned such that the dorsal contacts are in the Vim and the ventral contacts are in the PSA which may allow for more programming options.

\section{Pedunculopontine nucleus}

Postural instability is a significant issue for many patients with PD. Importantly it can contribute to falling which can lead to significant injury and hospitalization (e.g., hip fracture). Unfortunately this PD symptom is generally refractory to medical management and contemporary "classical" surgical targets including STN and GPi DBS. Therefore the PPN, a brainstem relay centre that plays a role in locomotion, has been targeted for DBS in investigational studies. The PPN is a predominantly cholinergic nucleus located posteriorly and caudally to the substantia nigra pars compacta ( $\mathrm{SNpc}$ ) extending to the level of the locus coeruleus. It receives input from the basal ganglia (STN and GPi) and has output to multiple subcortical targets including the thalamus and striatum in addition to targets within the brainstem and spinal cord. ${ }^{38-40}$ For the purposes of targeting it is important to note that there is some variability between institutions and as such no formal consensus for PPN DBS has been established. To date, only a handful of centres worldwide have published their experience with PPN DBS. ${ }^{39-45}$ There is significant variability in both targeting (i.e., unilateral vs. bilateral DBS, and multi-target DBS) and patient selection (i.e., those patients with dominant gait instability versus those that would be ideal candidates for STN or GPi DBS). The reported number of patients studied in the literature is small and there is a trend that PPN DBS, often at lower frequencies and in combination with STN, may provide improvements in reported number of falls and freezing of gait. However with blinded DBS on/off evaluation of UPDRS III no objective improvement has been documented. ${ }^{43,46}$

Given the current evidence, no firm recommendations can be made at this time and PPN DBS remains an investigational target. Further study is necessary to address appropriate patient selection, anatomical target selection, the role of combined targets and programming parameters.

\section{Should DBS for PD be Performed Unilaterally, Bilaterally OR Staged?}

In the vast majority of centres, PD patients who are suitable candidates for DBS are treated with upfront, bilateral stimulation of either the STN or GPi. ${ }^{13}$ Many centres opted for bilateral STN DBS because the reduced dopaminergic medication following unilateral stimulation often exacerbated the contralateral symptoms and could worsen gait. ${ }^{28}$ More recently, there has been some interest in unilateral targeting. ${ }^{47}$ Potentially compelling reasons to consider unilateral DBS include: 1) PD is an asymmetrical disease; 2) unilateral pallidotomy has long been known to produce some bilateral benefits in $\mathrm{PD} ;{ }^{48} 3$ ) the surgical risks of unilateral implantation may be reduced compared to a bilateral procedure; and 4) the stimulation-related side effects of bilateral DBS may be more severe than unilateral DBS. ${ }^{47,48} \mathrm{~A}$ few centres now routinely choose to perform unilateral DBS at initial implantation, followed by staged implantation of a contralateral lead at a later date. ${ }^{47,49}$ The immediate problem of this approach for the patient is that it requires two visits to the operating room with two stereotactic frame applications.

At the opposite end of the spectrum, some authors have suggested that there may be potential benefit from stimulation directed to multiple targets simultaneously (i.e., through leads implanted bilaterally into both the GPi and STN in the same patient). The multiple-target approach has been justified on the basis of a potential synergistic effect during stimulation at different nodes within the basal ganglia ${ }^{50,51}$ or, when applied in a staged fashion, as a means of rescuing the loss of therapeutic effect from stimulation at the initial target. ${ }^{52}$

There has so far been no prospective, randomized, blinded-assessment trial comparing unilateral DBS to best medical management in PD. However, class II data from the COMPARE trial $^{18}$ suggest that unilateral STN or GPi DBS both result in a significant improvement in motor scores as measured using the UPDRS-III. Several case series report that while the motor effects of unilateral DBS are more significant contralateral to the stimulated side, ipsilateral motor improvement is also observed following both $\mathrm{STN}^{53-58}$ and $\mathrm{GPi}^{59}$ stimulation. Ipsilateral motor benefit seems to be unrelated to which hemisphere is targeted ${ }^{59}$ and, while the underlying mechanism is uncertain, a single imaging study using positron emission tomography (PET) points to deactivation of the contralateral pallidum as a possible explanation. ${ }^{60}$ As for non-motor effects, the COMPARE trial showed that mood may be improved either by unilateral STN or GPi DBS, while-and in line with the bilateral DBS literature-unilateral STN stimulation results in verbal fluency impairment. ${ }^{61,63}$ That being said, verbal fluency may be more profoundly impaired following bilateral compared to unilateral STN stimulation. ${ }^{64}$

To date, there has been no prospective, randomized study directly comparing staged bilateral DBS to upfront bilateral DBS in PD. The existing data on staged DBS come exclusively from observational cohort studies in which unilateral DBS patients go on to have the contralateral side implanted; consequently, they are confounded by selection bias. With this in mind, Tanei et al. ${ }^{64}$ found that overall motor improvement measured with the UPDRS-III was similar in both bilateral and staged bilateral groups. Additionally, both a follow-up analysis of the COMPARE cohort $^{65}$ and a single centre study by Sung et al., ${ }^{49}$ found that the single best predictor of early staged implantation of the contralateral side was greater asymmetry in motor PD symptoms at baseline. There is no convincing evidence so far that a staged bilateral approach is safer or reduces the overall incidence of DBS-related adverse events.

Simultaneous, upfront implantation and stimulation of both the STN and GPi has been described by a single group. ${ }^{50,51}$ The authors found some evidence for a synergistic motor effect with two-target stimulation but these results have not yet been replicated, possibly due to the unwillingness of many centres to accept the increased surgical time and risk that may be incurred by the implantation of four (instead of the usual two) DBS leads. By contrast, several groups have reported on their experience with "rescue" DBS to recover lost therapeutic efficacy in patients 
following an initial period-typically several years—of good motor response to DBS. Successful rescue of motor benefit has been achieved both with bilateral STN DBS following initial GPi implantation $^{4,66-68}$ and with bilateral GPi DBS following initial STN implantation. ${ }^{52,69}$ However, there are insufficient data to conclude whether two-site stimulation in the rescue setting is actually synergistic, or whether stimulation at the initial target can be turned off once rescue target stimulation begins.

The absence of data from prospective, randomized, blinded-assessment trials points the way to future directions in the evaluation and implementation of unilateral, staged, and multipletarget strategies for DBS in PD. Though limited available evidence suggests that unilateral DBS at either the STN or GPi leads to significant motor improvement in PD, hard data from a randomized trial comparing unilateral DBS to best medical management are lacking. Such data would critically help to clarify the risk-benefit balance for unilateral DBS. Similarly, a randomized trial of staged bilateral versus upfront bilateral DBS would help to answer the question of whether staging may be safer for patients, and whether there exists a subset of PD patients who may be ideally suited for staging. Finally, additional work is required to elucidate whether there is a true synergistic effect when the STN and GPi are stimulated simultaneously, and to what degree this may be clinically relevant in patients with PD.

\section{ConClusion}

There is no universal consensus on the ideal target for DBS in patients with Parkinson's disease. Most prospective randomized studies have shown that patients with STN DBS had a similar clinical improvement compared to those with GPi DBS. If there have been differences in outcome between the two targets, it is often in scales that may not be relevant to the patient (i.e. improvement with stimulation when 'off' medications). However, there are a few predictable differences between these two common targets. First, STN DBS allows for a reduction in dopaminergic medications, which may benefit those with dopaminergic medication-induced behavioural disorders. Second, GPi has a direct anti-dyskinetic response, which may be beneficial for those with good mobility but disabling dyskinesia especially if they suffer anhedonia with low dopaminergic medications. Patients with disabling tremor despite good mobility (i.e. tremor dominant PD) will benefit from Vim DBS, as long as they do not progress to develop mobility issues. There is a need for new targets to ameliorate 'on' freezing of gait and balance issues. Currently, the PPN has basic science and animal model promise but no prospective blinded clinical confirmation of its effectiveness. Finally, most surgeons prefer a bilateral approach although there are cases with profoundly asymmetric symptoms that can benefit from a unilateral DBS (perhaps followed later by the contralateral side). Ultimately, there is no one approach that fits all patients. Clinicians should match their patient's individual symptoms with the DBS target that best ameliorates those symptoms.

\section{CONFLICTS OF INTEREST}

The symposium was sponsored by Medtronic and all speakers received honoraria and necessary transportation and accommodation. The final report presented above has no industry specific recommendations and was carefully screened to avoid any potential bias.
The scientific committee (CRH, RPM, AF and MP) selected three Canadian neurosurgeons (CH, SKK and TS) to share their knowledge of target selection for deep brain stimulation (DBS) of patients with Parkinson's disease (PD) and asked them to focus their discussion around the three controversial questions that currently face our field.

\section{DisCLOSURES}

Marina Picillo has the following disclosures: MJFF, Grant recipient, Grant; UHN, Salary, Employee; University of Salerno, Salary, Employee.

Tejas Sankar has the following disclosures: University of Alberta, Principal investigator, Research support/grant; Weston Foundation, Co-investigator, Research support/grant.

Alfonso Fasano has the following disclosures: Abbvie, Consultant/Advisor, Honoraria/Consulting fee; Boston Scientific, Consultant/Advisor, Honoraria/Consulting fee; Medtronic, Consultant/Advisor, Honoraria, Consulting fees, Research support; TEVA Canada, Consultant/Advisor, Honoraria; Novartis, Consultant/Advisor, Honoraria; UCB Pharma, Consultant/Advisor, Honoraria.

Clement Hamani has the following disclosures: St. Jude Medical, Consultant, Consulting fees.

Christopher Honey has the following disclosures: Medtronic, Speaker, Honoraria; Medtronic, Consultant, Consulting fees.

Suneil Kalia, Renato Puppi Munhoz and M. Panisset do not have anything to disclose.

\section{REFERENCES}

1. Wagle Shukla A, Okun MS. Surgical treatment of Parkinson's disease: patients, targets, devices, and approaches. Neurotherapeutics. 2014;11:47-59.

2. Burchiel KJ, Anderson VC, Favre J, Hammerstad JP. Comparison of pallidal and subthalamic nucleus deep brain stimulation for advanced Parkinson's disease: results of a randomized, blinded pilot study. Neurosurgery. 1999;45:1375-82.

3. Deep-Brain Stimulation for Parkinson's Disease Study Group. Deep-brain stimulation of the subthalamic nucleus or the pars interna of the globus pallidus in Parkinson's disease. N Engl J Med. 2001;345:956-63.

4. Volkmann J, Allert N, Voges J, Sturm V, Schnitzler A, Freund HJ. Long-term results of bilateral pallidal stimulation in Parkinson's disease. Ann Neurol. 2004;55:871-5.

5. Anderson VC, Burchiel KJ, Hogarth P, Favre J, Hammerstad JP. Pallidal vs subthalamic nucleus deep brain stimulation in Parkinson disease. Arch Neurol. 2005;62:554-60.

6. Rodriguez-oroz MC, Obeso JA, Lang AE, et al. Bilateral deep brain stimulation in Parkinson's disease: a multicentre study with 4 years follow-up. Brain. 2005;128:2240-9.

7. Volkmann J, Albanese A, Kulisevsky J, et al. Long-term effects of pallidal or subthalamic deep brain stimulation on quality of life in Parkinson's disease. Mov Disord. 2009;24:1154-61.

8. Weaver FM, Follett K, Stern M, et al. Bilateral deep brain stimulation vs best medical therapy for patients with advanced Parkinson disease: a randomized controlled trial. JAMA. 2009;301: 63-73.

9. Follett KA, Weaver FM, Stern M, et al. Pallidal versus subthalamic deep-brain stimulation for Parkinson's disease. N Engl J Med. 2010;362:2077-91.

10. Moro E, Lozano AM, Pollak P, et al. Long-term results of a multicenter study on subthalamic and pallidal stimulation in Parkinson's disease. Mov Disord. 2010;25:578-86.

11. Odekerken VJ, Van laar T, Staal MJ, et al. Subthalamic nucleus versus globus pallidus bilateral deep brain stimulation for 
advanced Parkinson's disease (NSTAPS study): a randomised controlled trial. Lancet Neurol. 2013;12:37-44.

12. Deuschl G, Paschen S, Witt K. Clinical outcome of deep brain stimulation for Parkinson's disease. Handb Clin Neurol. 2013;116:107-28.

13. Bronstein JM, Tagliati M, Alterman RL, et al. Deep brain stimulation for Parkinson disease: an expert consensus and review of key issues. Arch Neurol. 2011;68:165.

14. Castrioto A, Volkmann J, Krack P. Postoperative management of deep brain stimulation in Parkinson's disease. Handb Clin Neurol. 2013;116:129-46.

15. Voon V, Howell NA, Krack P. Psychiatric considerations in deep brain stimulation for Parkinson's disease. Handb Clin Neurol. 2013;116:147-54.

16. Castrioto A, Lhommée E, Moro E, Krack P. Mood and behavioural effects of subthalamic stimulation in Parkinson's disease. Lancet Neurol. 2014;13:287-305.

17. Sankar T, Lozano AM. Surgical approach to 1-dopa-induced dyskinesias. Int Rev Neurobiol. 2011;98:151-71.

18. Okun MS, Fernandez HH, Wu SS, et al. Cognition and mood in Parkinson's disease in subthalamic nucleus versus globus pallidus interna deep brain stimulation: the COMPARE trial. Ann Neurol. 2009;65:586-95.

19. Benabid AL, Pollak P, Louveau A, Henry S, De Rougemont J. Combined (thalamotomy and stimulation) stereotactic surgery of the VIM thalamic nucleus for bilateral Parkinson disease. Appl Neurophysiol. 1987;50:344-6.

20. Benabid AL, Pollak P, Hommel M, Gaio JM, De Rougemont J, Perret J. Treatment of Parkinson tremor by chronic stimulation of the ventral intermediate nucleus of the thalamus. Rev Neurol (Paris). 1989;145:320-3.

21. Benabid AL, Pollak P, Gervason C, et al. Long-term suppression of tremor by chronic stimulation of the ventral intermediate thalamic nucleus. Lancet. 1991;337:403-6.

22. Olanow CW, Brin MF, Obeso JA. The role of deep brain stimulation as a surgical treatment for Parkinson's disease. Neurology. 2000;55(Suppl 6):S60-6.

23. Pahwa R, Lyons KE, Wilkinson SB, et al. Long-term evaluation of deep brain stimulation of the thalamus. J Neurosurg. 2006;104:506-12.

24. Rehncrona S, Johnels B, Widner H, Törnqvist AL, Hariz M, Sydow O. Long-term efficacy of thalamic deep brain stimulation for tremor: double-blind assessments. Mov Disord. 2003;18:163-70.

25. Sydow O, Thobois S, Alesch F, Speelman JD. Multicentre European study of thalamic stimulation in essential tremor: a six year follow up. J Neurol Neurosurg Psychiatr. 2003;74:1387-91.

26. Zesiewicz TA, Elble RJ, Louis ED, et al. Evidence-based guideline update: treatment of essential tremor: report of the Quality Standards subcommittee of the American Academy of Neurology. Neurology. 2011;77:1752-5.

27. Lukins TR, Tisch S, Jonker B. The latest evidence on target selection in deep brain stimulation for Parkinson's disease. J Clin Neurosci. 2014;21:22-7.

28. Pollak P, Fraix V, Krack P, et al. Treatment results: Parkinson's disease. Mov Disord. 2002;17(Suppl. 3):S75-83.

29. Rodriguez-Oroz MC, Moro E, Krack P. Long-term outcomes of surgical therapies for Parkinson's disease. Mov Disord. 2012;27:1718-28.

30. Naoki T, Ryoma M, Ryuji K, Satoshi G. Current Use of Thalamic Vim Stimulation in Treating Parkinson's Disease, A Synopsis of Parkinson's Disease, Rana AQ (Ed.), ISBN: 978-953-51-1229-7, InTech, DOI: 10.5772/57105. Available from:http://www. intechopen.com/books/a-synopsis-of-parkinson-s-disease/current-useof-thalamic-vim-stimulation-in-treating-parkinson-s-disease.

31. Hariz MI, Krack P, Alesch F, et al. Multicentre European study of thalamic stimulation for parkinsonian tremor: a 6 year follow-up. J Neurol Neurosurg Psychiatr. 2008;79:694-9.

32. Kumar R, Lozano AM, Sime E, Lang AE. Long-term follow-up of thalamic deep brain stimulation for essential and parkinsonian tremor. Neurology. 2003;61:1601-4.

33. Schuurman PR, Bosch DA, Merkus MP, Speelman JD. Long-term follow-up of thalamic stimulation versus thalamotomy for tremor suppression. Mov Disord. 2008;23:1146-53.
34. Blomstedt P, Sandvik U, Tisch S. Deep brain stimulation in the posterior subthalamic area in the treatment of essential tremor. Mov Disord. 2010;25:1350-6.

35. Xie T, Bernard J, Warnke P. Post subthalamic area deep brain stimulation for tremors: a mini-review. Transl Neurodegener. 2012;1:20.

36. Plaha P, Ben-Shlomo Y, Patel NK, Gill SS. Stimulation of the caudal zona incerta is superior to stimulation of the subthalamic nucleus in improving contralateral parkinsonism. Brain. 2006;129:1732-47.

37. Sandvik U, Koskinen LO, Lundquist A, Blomstedt P. Thalamic and subthalamic deep brain stimulation for essential tremor: where is the optimal target? Neurosurgery. 2012;70:840-5.

38. Benarroch EE. Pedunculopontine nucleus: functional organization and clinical implications. Neurology. 2013;80:1148-55.

39. Hamani C, Moro E, Lozano AM. The pedunculopontine nucleus as a target for deep brain stimulation. J Neural Transm. 2011;118:1461-8.

40. Tykocki T, Mandat T, Nauman P. Pedunculopontine nucleus deep brain stimulation in Parkinson's disease. Arch Med Sci. 2011;4:555-64.

41. Khan S, Mooney L, Plaha P, et al. Outcomes from stimulation of the caudal zona incerta and pedunculopontine nucleus in patients with Parkinson's disease. Br J Neurosurg. 2011;25:273-80.

42. Khan S, Gill SS, Mooney L, et al. Combined pedunculopontinesubthalamic stimulation in Parkinson disease. Neurology. 2012;78:1090-5.

43. Moro E, Hamani C, Poon YY, et al. Unilateral pedunculopontine stimulation improves falls in Parkinson's disease. Brain. 2010;133:215-24.

44. Stefani A, Lozano AM, Peppe A, et al. Bilateral deep brain stimulation of the pedunculopontine and subthalamic nuclei in severe Parkinson's disease. Brain. 2007;130:1596-607.

45. Thevathasan W, Coyne TJ, Hyam JA, et al. Pedunculopontine nucleus stimulation improves gait freezing in Parkinson disease. Neurosurgery. 2011;69:1248-53.

46. Ferraye MU, Debû B, Fraix V, Krack P, Charbardès S, Seigneuret E, Benabid A-L, Pollak P. Subthalamic nucleus versus pedunculopontine nucleus stimulation in Parkinson disease: synergy or antagonism? J. Neural Transm. 2011;118:1469-75.

47. Alberts JL, Hass CJ, Vitek JL, Okun MS. Are two leads always better than one: an emerging case for unilateral subthalamic deep brain stimulation in Parkinson's disease. Exp Neurol. 2008;214:1-5.

48. Lang AE, Lozano AM, Montgomery E, Duff J, Tasker R, Hutchinson W. Posteroventral medial pallidotomy in advanced Parkinson's disease. N Engl J Med. 1997;337:1036-42.

49. Sung VW, Watts RL, Schrandt CJ, et al. The relationship between clinical phenotype and early staged bilateral deep brain stimulation in Parkinson disease. J Neurosurg. 2013;119:1530-6.

50. Mazzone P, Brown P, Dilazzaro V, et al. Bilateral implantation in globus pallidus internus and in subthalamic nucleus in Parkinson's disease. Neuromodulation. 2005;8:1-6.

51. Peppe A, Pierantozzi M, Bassi A, et al. Stimulation of the subthalamic nucleus compared with the globus pallidus internus in patients with Parkinson disease. J Neurosurg. 2004;101: 195-200.

52. Minafra B, Fasano A, Pozzi NG, Zangaglia R, Servello D, Pacchetti C. Eight-years failure of subthalamic stimulation rescued by globus pallidus implant. Brain Stimul. 2014;7:179-81.

53. Germano IM, Gracies JM, Weisz DJ, Tse W, Koller WC, Olanow $\mathrm{CW}$. Unilateral stimulation of the subthalamic nucleus in Parkinson disease: a double-blind 12-month evaluation study. J Neurosurg. 2004;101:36-42.

54. Kumar R, Lozano AM, Sime E, Halket E, Lang AE. Comparative effects of unilateral and bilateral subthalamic nucleus deep brain stimulation. Neurology. 1999;53:561-6.

55. Agostino R, Dinapoli L, Modugno N, et al. Ipsilateral sequential arm movements after unilateral subthalamic deep-brain stimulation in patients with Parkinson's disease. Mov Disord. 2008;23: 1718-24.

56. Linazasoro G, Van Blercom N, Lasa A. Unilateral subthalamic deep brain stimulation in advanced Parkinson's disease. Mov Disord. 2003;18:713-6.

57. Chung SJ, Jeon SR, Kim SR, Sung YH, Lee MC. Bilateral effects of unilateral subthalamic nucleus deep brain stimulation in advanced Parkinson's disease. Eur Neurol. 2006;56:127-32. 
58. Tabbal SD, Ushe M, Mink JW, et al. Unilateral subthalamic nucleus stimulation has a measurable ipsilateral effect on rigidity and bradykinesia in Parkinson disease. Exp Neurol. 2008;211:234-42.

59. Shemisa K, Hass CJ, Foote KD, et al. Unilateral deep brain stimulation surgery in Parkinson's disease improves ipsilateral symptoms regardless of laterality. Parkinsonism Relat Disord. 2011;17:745-8.

60. Arai N, Yokochi F, Ohnishi T, et al. Mechanisms of unilateral STNDBS in patients with Parkinson's disease : a PET study. J Neurol. 2008;255:1236-43.

61. Mikos A, Zahodne L, Okun MS, Foote K, Bowers D. Cognitive declines after unilateral deep brain stimulation surgery in Parkinson's disease: a controlled study using Reliable Change, part II. Clin Neuropsychol. 2010;24:235-45.

62. Zahodne LB, Okun MS, Foote KD, et al. Cognitive declines one year after unilateral deep brain stimulation surgery in Parkinson's disease: a controlled study using reliable change. Clin Neuropsychol. 2009;23:385-405.

63. Sjoberg RL, Lidman E, Haggstrom B, et al. Verbal fluency in patients receiving bilateral versus left-sided deep brain stimulation of the subthalamic nucleus for Parkinson's disease. J Int Neuropsychol Soc. 2012;18:606-11.
64. Tanei T, Kajita Y, Kaneoke Y, Takebayashi S, Nakatsubo D, Wakabayashi T. Staged bilateral deep brain stimulation of the subthalamic nucleus for the treatment of Parkinson's disease. Acta Neurochir (Wien). 2009;151:589-94.

65. Taba HA, Wu SS, Foote KD, et al. A closer look at unilateral versus bilateral deep brain stimulation: results of the National Institutes of Health COMPARE cohort. J Neurosurg. 2010;113:1224-9.

66. Houeto JL, Bejjani PB, Damier P, et al. Failure of long-term pallidal stimulation corrected by subthalamic stimulation in PD. Neurology. 2000;55:728-30.

67. Hammerstad J, Burchiel K, Anderson V, Nutt J. Failure of long-term pallidal stimulation corrected by subthalamic stimulation in PD. Neurology. 2001;57:566-7.

68. Allert N, Lehrke R, Sturm V, Volkmann J. Secondary failure after ten years of pallidal neurostimulation in a patient with advanced Parkinson's disease. J Neural Transm. 2010;117:349-51.

69. Allert N, Schnitzler A, Sturm V, Maarouf M. Failure of long-term subthalamic nucleus stimulation corrected by additional pallidal stimulation in a patient with Parkinson's disease. J Neurol. 2012;259:1244-6. 